\title{
Linking flow, water quality and potential effects on aquatic biota within the Reserve determination process
}

\author{
HL Malan* and JA Day \\ Freshwater Research Unit, Department of Zoology, University of Cape Town, Rondebosch 7701, South Africa
}

\begin{abstract}
Linking the potential effects of altered water quality on aquatic biota, that may result from a change in the flow (discharge) regime, is an essential step in the maintenance of riverine ecological functioning. Determination of the environmental flow requirement of a river (as well as other activities, such as classifying the resource) is known in South Africa as determining the "ecological Reserve". This paper describes the philosophy behind the incorporation of water quality concerns in, as well as the constraints that are likely to be in operation during a Reserve determination. Three simple, predictive tools that have been developed for routine use in ecological Reserve assessments are described in this paper. Flow-concentration modelling can be used to predict the water quality that is likely to result from a given, prescribed flow regime. The Biotic Protocol attempts to provide an assessment of the likely implications of the predicted water quality for aquatic macroinvertebrates. Concentration time-series modelling can be used to rank complex flow scenarios with regard to potential consequences for water quality. Finally, a framework is presented for incorporating predictions of water quality and the implications for the aquatic biota in ecological Reserve assessments.
\end{abstract}

Keywords: rivers, water quality, ecological Reserve, environmental flows, instream flow requirement

\section{Introduction}

The South African National Water Act (No. 36 of 1998), is unusual amongst existing legislation internationally, because it recognises that in order to sustain the goods and services that are provided by rivers (e.g. water, riverine flora, fauna and recreational opportunities) it is necessary to conserve the entire aquatic ecosystem (DWAF, 1999). Protection of the biotic components of the system and maintenance of ecosystem functioning at a given required level entail ensuring that the abiotic aspects (the required amount and variability of flow, water quality, fluvial geomorphology) are also addressed. This is recognised in the National Water Act by the provision of a water quantity "Reserve", which is the amount of water and timing of flow that are required to maintain a given level of ecosystem functioning. The Act also stipulates that a water quality component to the Reserve should also be set which represents the values of physical variables and concentrations of chemical constituents that should not be exceeded in a particular reach of a river. But flow and water quality are intimately linked and if flow is altered, water quality will also frequently change (Gregory and Walling, 1973; Jenkins, 1989; Malan and Day, 2002a). One of the most obvious reasons (but by no means the only one) for this effect is that the dilution capacity of the system is likely to be altered. For example, the dilution capacity will be reduced if the recommended environmental flow requirement (also known in South Africa as the "instream flow requirement" or "IFR") represents a smaller quantity of water than that available at present. If amelioration of point sources of pollution does not occur, the concentration of at least some instream chemical components is likely to increase. Water quality in turn is linked to biotic response, and the provision of water of suitable quality is essential to maintain healthy populations

\footnotetext{
* To whom all correspondence should be addressed.

谓 +2721650 3872; fax: +2721650 3301;

e-mail: hmalan@botzoo.uct.ac.za

Received 15 January 2003; accepted in revised form 27 March 2003.
}

of aquatic organisms (Smith et al., 1999). Different taxa of, for example, macroinvertebrates or fish exhibit differing tolerances to individual water quality variables (Dallas and Day, 1993). If water quality is altered some taxa may thrive, whereas others, because of the unsuitability of the surrounding medium, may disappear from that stretch of river (Perry et al., 1996). Thus, in order to ensure that the entire ecosystem is conserved, it is necessary when setting the Reserve for a river reach, to be able to predict the effect of a given flow regime on water quality and the implications of the resulting water quality for the aquatic biota.

An ecological Reserve determination, as currently carried out in South Africa, involves assessing the IFR, but the process goes further in that the water resource is classified according to its current ecological state, and the level of protection for which the resource will be managed is determined. In addition, resource quality objectives, or benchmarks, are set for various components of the ecosystem including water quality, geomorphology, riparian vegetation, fish, and macroinvertebrates. There are different levels of Reserve determination ranging from planning estimates, to fullscale comprehensive assessments of the IFR. In terms of the National Water Act, at least a preliminary level of Reserve determination needs to be made for each significant water resource, before licences can be issued for abstraction and for other forms of water use. Full Reserve determinations must also be carried out for all significant water bodies (DWAF, 1999; O'Keeffe, 2000).

Due to excessive abstraction, regulation of flow and release of effluent discharge, increasing demands are being made on many rivers. Thus, it is imperative that the Reserve be assessed and implemented for heavily utilised water resources as soon as possible. Yet, although it has long been recognised that water is a limited and vital resource, the amount of money that can be allocated to the protection and management of that resource is relatively small. In addition, there is often a lack of qualified personnel to manage these assets. Thus any methods that are developed and used in the routine determination and implementation of the Reserve need to be reasonably accurate, but also rapid, simple to use, and inexpensive. 


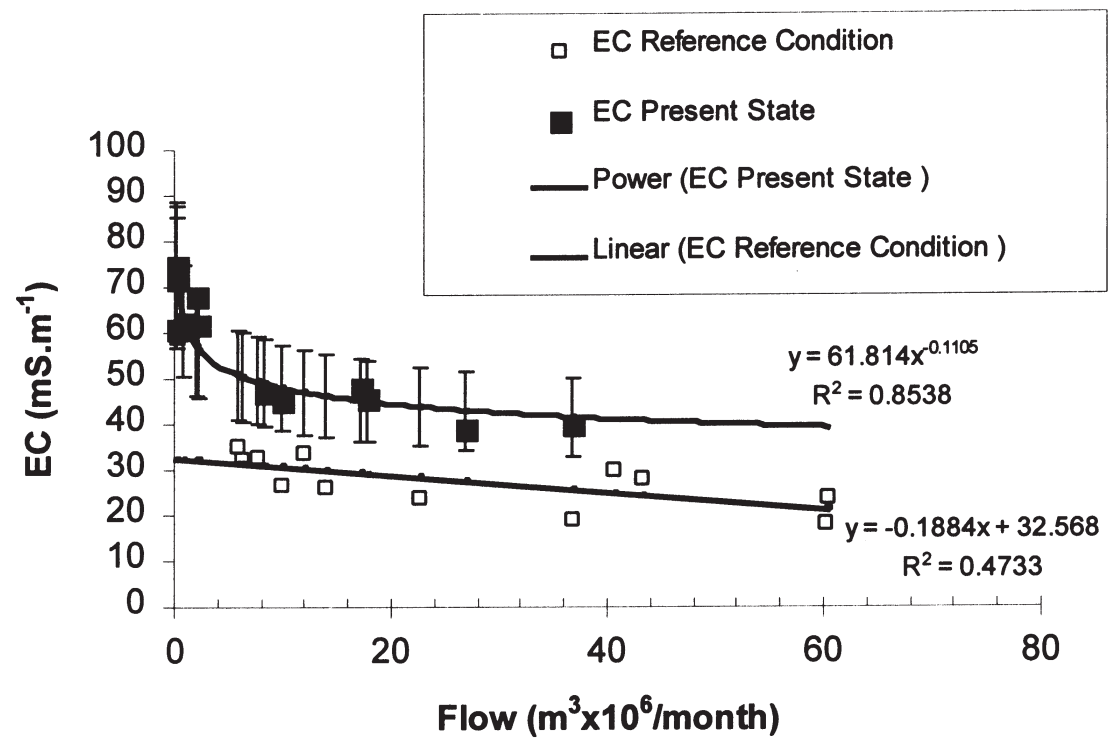

Figure 1

Q-C plot for electrical conductivity (EC) at a site on the Olifants River (Mpumalanga). Monthly median values for both the reference condition and the present state are shown as well as the $95 \%$ confidence interval for the latter.

There also needs to be a range of tools for different levels of application of the Reserve. For example, sophisticated water quality modelling should be used for key water resources that are under pressure from conflicting user demands (Malan and Day, $2002 \mathrm{~b}$ ). The tools that are presented in this paper are for routine application and are designed to be pragmatic, yielding estimates rather than precise quantitative results. Another major constraint in the determination of the Reserve for rivers in South Africa is the paucity of relevant hydrological, and to an even greater extent, the lack of water quality and biomonitoring data. Our understanding of the quantitative relationships between water quality and biotic responses is also very limited.

In this paper, consideration is given to the philosophy of how water quality should be incorporated into Reserve determinations, followed by a brief description of several tools that have been developed to aid in these assessments. Finally, a framework is proposed for including predictions of changes in water quality and the implications for the biota in the Reserve process.

\section{Incorporation of water quality in Reserve determinations}

A principle central to the notion of the ecological Reserve is that the recommended flow regime should represent the flow required to maintain the hydraulic and geomorphological habitat required by the biota. It should not be set in order to bring about dilution of pollutants in a system so that they fall within the limits specified by the resource quality objectives for individual chemical constituents (Tharme and King, 1998; Palmer and Rossouw, 2000). Only in cases in which some water quality constituents are naturally elevated may the amount of water comprising the Reserve be increased for the purpose of dilution. For example, in situations where elevated instream concentrations of salts derive from natural rather than from anthropogenic origins, decreased flow brought about by upstream abstraction may lead to unacceptably high salinity levels (higher than are likely to occur under natural flows). In such cases the amount of water constituting the Reserve should be adjusted and some form of water quality modelling employed to predict the salinity resulting from the recommended flow regime. If, on the other hand, elevated salinity is due to anthropogenic activities in the catchment, the water quantity of the Reserve should not be adjusted. Water managers then need to decide whether pollution of the river should be reduced, or if "extra" water, over and above that of the Reserve, should be supplied to dilute the contaminants to an appropriate level.

\section{Predictive tools for use in ecological Reserve determinations}

Several tools are presently being developed to link flow, water quality and biotic responses within ecological Reserve determinations. Three of these tools are briefly described below, whilst a more comprehensive discussion is given in Malan and Day (2002b)

\section{Flow-concentration (Q-C) modelling}

Flow-concentration modelling can be used to predict instream concentrations of chemical constituents that will result from a proposed flow regime. The method is essentially based on the use of rating curves, which have long been established in the literature (Gregory and Walling, 1973; Sidle, 1988). For a given site on a river, median monthly concentrations for each water quality variable, and mean monthly flow values are derived. The data used would normally be obtained from the chemical monitoring programme maintained by the Department of Water Affairs and Forestry (DWAF), but data from other sources such as water boards could also be used. Calculations are performed separately for the current state of the system (termed the "present ecological state" (PES)) and for the system under natural (or minimally impaired) conditions (the "reference condition" (RC)). Data are entered into standardised spreadsheet templates and plots of flow versus concentration (called "Q-C" plots) are generated. A regression line is fitted through the data points and this relationship is used to make predictions of the instream concentration that will arise for a given, recommended monthly flow.

Figure 1 shows an example of a Q-C plot for electrical conductivity (EC) at a site on the Olifants River (Mpumalanga). The monthly median values for the RC and PES as well as the regression line for each state are shown. In addition, the $95 \%$ confidence interval for the PES is indicated. The method used to derive these statistical parameters is discussed in Malan et al. (2003). It can be seen that the present-day EC levels decrease with increasing flow (due to dilution). Furthermore, present-state concentrations are 
above those of the $\mathrm{RC}$, indicating that due to pollution, salinity levels in that part of the Olifants River, are currently elevated.

There are assumptions and limitations in the Q-C method, which need to be understood when making predictions of water quality:

- Firstly, factors other than flow can affect instream concentrations, and as a result, predictions made using Q-C modelling are estimates.

- Secondly, predictions are valid only if under the new flow regime the loading of contaminants and the proportions of flow from different sources will be the same as those used to formulate the Q-C model.

- Thirdly, the method is not suitable for situations in which the instream concentration of a constituent increases with flow. This type of relationship is often exhibited by non-point sources of pollutants, such as nitrates in rivers of catchments dominated by agricultural land use. Due to wash-off from the surrounding land, instream concentrations of nitrate usually increase with increasing flow, at least in the low-flow portion of the discharge range. If the instream flow is reduced, for example by abstraction, the load washing into the river may well remain the same, and it therefore cannot necessarily be assumed that instream concentrations will decrease as would be predicted from the Q-C plot.

These are the major assumptions and limitations in the method, although others also apply. The modelling technique is most effective for conservative constituents. Nutrients can also be modelled, although they sometimes exhibit considerable scatter with flow due to the many processes that affect instream concentration. This modelling method is not suitable for making predictions of temperature or dissolved oxygen, since the former is a physical variable, rather than a chemical entity. The concentration of dissolved oxygen in the water column is complicated by many factors including hydraulic turbulence, temperature and the presence of aquatic plants, and is not amenable to the simple approach used in this method.

Despite these limitations Q-C modelling can be very useful for screening sites to determine whether, under a proposed flow regime and without amelioration of pollution sources, the water quality component of the Reserve is likely to be attained. It can also be used, in the absence of pollution control, to estimate the flow required to dilute given chemical constituents to a suitable concentration. Finally, Q-C modelling can be used to calculate the approximate values of the highest instream concentrations and thus, the worst water quality that is likely to occur under a given flow regime, as well as the month(s) of the year in which this will occur.

\section{The Biotic Protocol}

The Biotic Protocol provides for the structured collation of all relevant information in order to make an assessment of the likely effects of a proposed flow regime (and hence the resulting water quality scenario) on the aquatic biota (Malan and Day, 2002b). Macroinvertebrates have been the major focus in the development of this tool, but provided that data are available linking water quality and presence/absence of taxa, it could potentially be extended to other biotic components such as fish. The Protocol primarily makes use of existing national databases containing biological and water quality data that have been collected simultaneously. These are the "Rivers" database in which the biomonitoring data from the South African River Health project are stored (Fowler et al., 2000), and the "Biological and chemical database (Biobase)", which contains historical records of macroinvertebrate and water quality sampling (Dallas and Janssens, 1998).

Using water quality modelling (for example, the Q-C method, or some other model e.g. QUAL2E, (Brown and Barnwell, 1987)), monthly concentrations of key chemical constituents that will occur under a recommended flow regime can be predicted. As the first step of the Biotic Protocol, the highest concentrations that will occur under natural and present-day flow conditions can be matched up with the predicted maximum concentrations under the proposed (recommended) flow regime (termed the "future predicted state" (FPS)). In order to assess the current water quality status of a given river reach and how this is likely to change under the proposed flow regime, these maximum values are then compared with the South African Water Quality Guidelines (DWAF, 1996). National and international databases can also be consulted in order to compare the predicted maximum values for each water quality constituent with ecotoxicological parameters (e.g. with the LOEC - the lowest observable effect concentration, or the AEC - the acute effects value). From the above information, and using expert judgement the three most important (in terms of being impacted and likely to exert a deleterious effect on the biota) water quality variables are selected. The Biobase and Rivers databases are then consulted for sampling instances representing comparable water quality conditions and data are extracted either for the specific river in question, or for similar reaches of rivers in the same geographical region (ecoregion). The lists of invertebrate taxa occurring in samples that were obtained under each of the three water quality scenarios (the "reference condition" (RC), "present ecological state" (PES) and the "future predicted state" (FPS)) are then compared. Possible shifts in community composition, including the occurrence of nuisance taxa and the loss of rare/key species, can be identified. Theoretical SASS scores (SASS is the South African Scoring System, a macroinvertebrate index of water quality (Chutter, 1998) can be calculated. From this index an estimate can be made of the ecological Reserve "class" that the river is likely to fall into with regard to macroinvertebrates, under the new flow (and hence water quality) regime (DWAF, 1999). The class needs to be derived using expert knowledge of the given river site, consideration being given to factors such as the potential effects of alterations to hydraulic habitat, and antagonistic/synergistic effects between water quality constituents. A summary of the Biotic Protocol is given in Table 1 and its application is explained in detail in Malan and Day (2002b).

Table 2 shows the results of a hypothetical application of the Protocol to illustrate the type of results that can be obtained. Lists of the macroinvertebrate taxa recorded from different sampling occasions and the calculated theoretical SASS scores are shown. In addition, the concentrations of the water quality constituents deemed to be critical at that site (fluoride, TDS and sulphate) are recorded. It is on the basis of fluoride concentration that the sampling data have been divided into water quality comparable to the "reference condition (RC)", "present ecological state (PES)" and "future predicted state (FPS)". In this specific example, the future water quality was predicted to be improved compared to the present-day water quality. The table shows that invertebrate families and higher taxa largely lost from the system in this example, compared to the "reference condition" include: Nantantia and Oligoneuridae. Taxa that may be regained in the system under the recommended flow regime (and associated improved water quality) include: Ancylidae, Belastomatidae, Elmidae/Dryopidae, Notonectidae, Physidae, and Veliidae. 


\section{TABLE 1 \\ Summary of the Biotic Protocol (see text for a description of the terms used)}

i) Using water quality modelling, tabulate the maximum monthly values for each water quality variable. This is carried out separately for the:

a) reference condition;

b) present ecological state; and

c) future predicted state (i.e. under the recommended flow regime).

ii) Compare the maximum values with the $S A$ Water Quality Guidelines and identify the two or three water quality variables likely to pose the most serious risk to the biota.

iii) Compare ecotoxicological parameters, if available, with the maximum values in order to estimate the toxicity of the variable in question.

iv) Consult the Biobase and Rivers database for sampling data comparable to the water quality of the reference condition for:

a) the specific river in question; and

b) similar systems (i.e. in the same ecoregion and type of river).

v) Consult the Biobase and Rivers database for sampling data comparable to the water quality of the future predicted state for:

a) the specific river in question; and

b) similar systems (i.e. the same ecoregion, and type of river).

vi) Compare taxa lists for the reference condition, present ecological state and future predicted state. Derive a theoretical SASS score and a tentative assessment class (using DWAF, 1999) for the future predicted state for macroinvertebrates.

vii) Include input from any other biotic tolerance indices that may be relevant, e.g. for fish.

viii) Synthesise a scenario for the aquatic biota that is likely to be the consequence of the proposed change in discharge. Assign the future assessment class (A-F).

The Biotic Protocol can be used to assess whether, under the recommended flow regime and the current level of pollution loading, water quality conditions will allow the resource quality objectives with regard to aquatic invertebrates to be attained. Because aquatic ecosystems are complex and biotic responses to environmental variables are not always easy to predict, at best only estimates can be obtained. There are several assumptions and limitations implicit in this method:

- Firstly, any change or loss of hydraulic habitat, refugia or recolonisation sites that may occur under the new flow scenario are not taken directly into account.

- Secondly, because of gaps in the biotic data, a given taxon may not be found in the database under particular conditions of water chemistry even if it might well tolerate those conditions.
- Thirdly, the Biotic Protocol makes use of the maximum concentration of a chemical constituent that is likely to occur during the year. The length of time that organisms would be exposed to that concentration is also an important consideration that is not presently taken into account. The current emphasis is on the magnitude, rather than on the duration, timing, frequency or rate of change of the predicted altered concentration.

- Finally, the lack of data linking water quality and the presence/ absence of macroinvertebrates in some regions of the country is, at the moment, the most serious limitation to the use of the protocol. This deficiency is being addressed, however, through the South African River Health biomonitoring programme.

\section{Concentration time-series and exceedance curves}

For the purpose of comparing different complex flow management scenarios in South Africa, flow time-series can be generated to incorporate the monthly, recommended flows (as specified in the Reserve) for maintenance and drought conditions (Louw et al., 2000). The site-specific relationships between flow and instream concentration that are derived using Q-C modelling can be used to generate concentration time-series for a critical chemical constituent. This is similar to the general approach described by Waddle (1998), who reported the use of time-series and exceedance curves of suitable instream habitat (as weighted usable area) derived from PHABSIM (physical habitat simulation system, the primary component of the environmental flow methodology, "Instream Flow Incremental Methodology" (Milhous et al., 1989)). Concentration exceedance curves can be derived from concentration time-series (Fig. 2). In this way it is possible to predict and assess the consequences (with regard to key water quality constituents) of different flow scenarios. Because major approximations are made in the preparation of concentration time-series, they should not be used to make quantitative predictions but can be useful for comparing and ranking flow time-series in terms of the likely water quality that will result from each. One of the problems that needs to be addressed in this approach is how to combine different water quality variables. Some work has gone towards using ecotoxicological data to extrapolate from the predicted concentration to the stress likely to be experienced by aquatic macroinvertebrates (Scherman et al., 2003).

\section{A proposed framework for incorporating predictions of water quality and biotic responses in the Reserve}

Table 3 presents a proposed framework for incorporating predicted alterations of water quality and likely implications of these for the aquatic biota, into the Reserve process. The framework is compatible with both methods presently used in South Africa for assessing environmental flow requirements (EFRs), namely, the Building Block Methodology (King and Louw, 1998) and DRIFT (Downstream Response to Imposed Flow Transformations (King et al., in press). Both methods assess the flow requirement at discrete sites ("IFR sites") that are considered to be representative of the entire river reach in which they are situated, and both have an environmental flow requirement workshop as one of the central activities.

The process consists of three main phases:

- Firstly, the water resource is examined with regard to ecoregion, point sources of pollution and catchment land use. All pertinent water quality data are assembled and examined for com- 


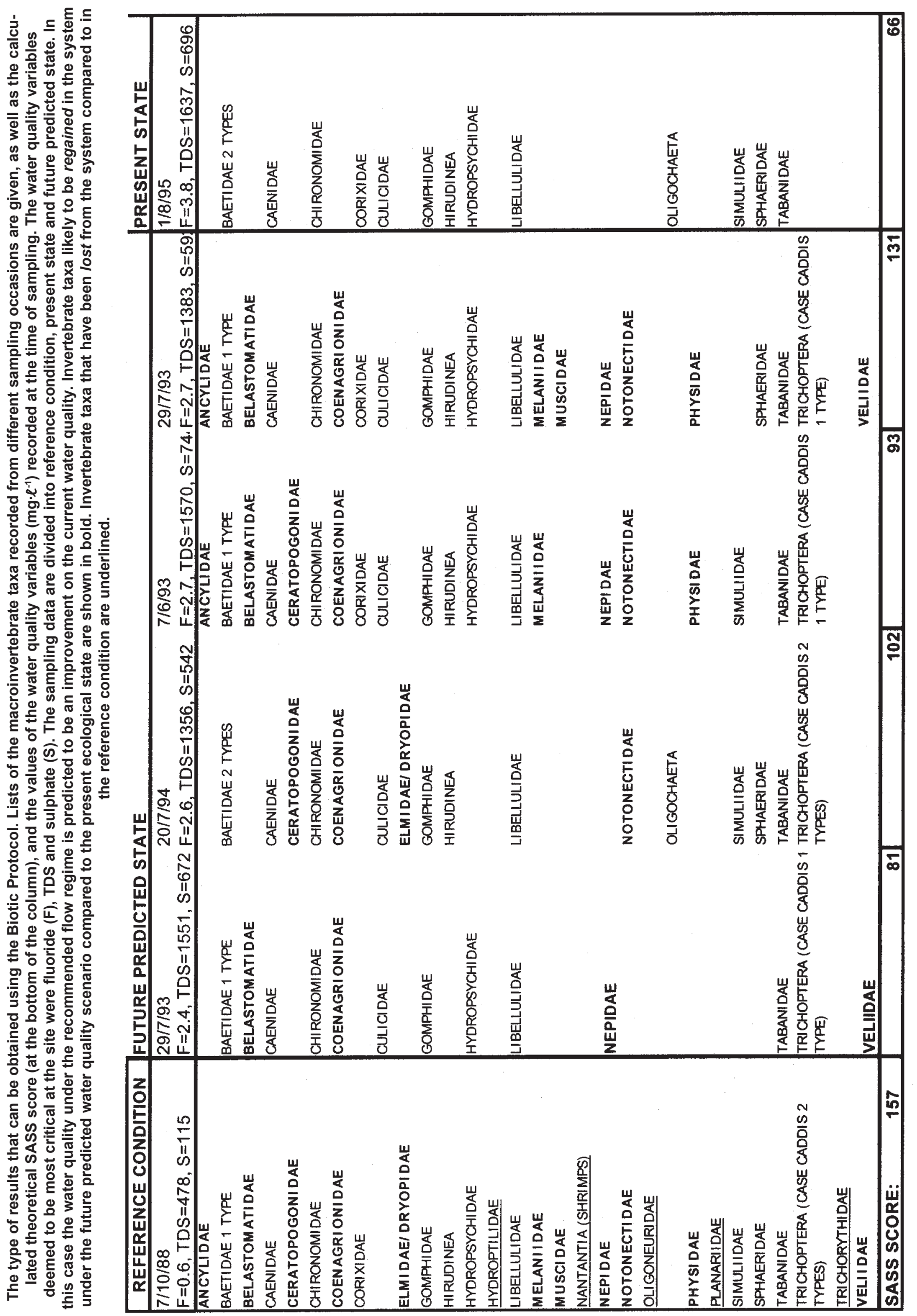


TABLE 3

Framework for the incorporation of predictions of water quality, as well as the implications of altered water quality for the biota, in Reserve assessments. Three main phases are indicated, which are subdivided into steps. Individual work components are shown, as well as the product arising from each and the step in which the product will be used.

$(W Q=$ water quality, RC = reference condition, $\mathrm{PES}=$ present ecological state, $\mathrm{RQO}$ s = resource quality objectives, IFR = instream flow requirement)

\begin{tabular}{|c|c|c|c|c|}
\hline Phase & Step & Work component & Product & Use of product \\
\hline \multirow{11}{*}{ 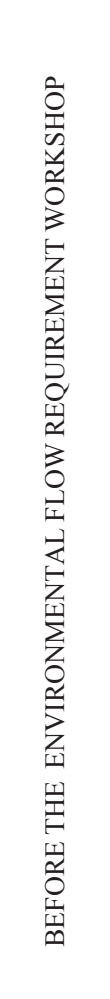 } & \multirow{7}{*}{ 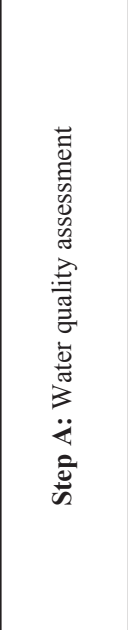 } & $\begin{array}{l}\text { 1. Identify resource } \& \text { delineate boundaries, } \\
\text { choose IFR sites etc. }\end{array}$ & Maps of resource. & \multirow[t]{2}{*}{ Used for entire process } \\
\hline & & $\begin{array}{l}\text { 2. Identify ecoregions, significant hydrological } \\
\text { features, point sources, etc. }\end{array}$ & $\begin{array}{l}\text { WQ reaches (i.e. reaches with } \\
\text { homogeneous WQ). }\end{array}$ & \\
\hline & & 3. Determine reference condition. & $\begin{array}{l}\text { Monthly median values for each } \\
\text { WQ variable. }\end{array}$ & Step B \\
\hline & & 4. Determine present ecological state. & $\begin{array}{l}\text { Monthly median values for each } \\
\text { WQ variable. }\end{array}$ & Step B \\
\hline & & 5. Assign provisional Ecological Reserve Class. & $\begin{array}{l}\text { Required level of protection for } \\
\text { each sub-section of river. }\end{array}$ & \\
\hline & & 6. Assign WQ Reserve. & RQOs for each variable and site. & Step C \\
\hline & & 7. Record findings. & WQ Starter document. & Used for entire process \\
\hline & \multirow{4}{*}{ 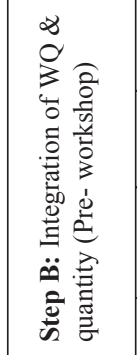 } & $\begin{array}{l}\text { 8. Check RC \& PES monthly median values for } \\
\text { suitability for modelling. }\end{array}$ & & \\
\hline & & $\begin{array}{l}\text { 9. Consult with hydrologist. Obtain appropriate } \\
\text { discharge data. }\end{array}$ & & \\
\hline & & 10. Prepare Q-C modelling spreadsheets. & $\begin{array}{l}\text { Q-C relationships for each variable } \\
\text { at each IFR site. }\end{array}$ & Step $C$ andStep $F$ \\
\hline & & 11. Prepare concentration exceedance curves. & Concentration exceedance curves. & \\
\hline \multirow{3}{*}{ 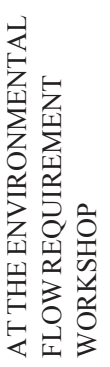 } & \multirow{3}{*}{ 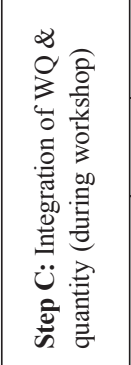 } & $\begin{array}{l}\text { 12. Use Q-C modelling to predict } \\
\text { concentrations. }\end{array}$ & $\begin{array}{l}\text { The "Water quality consequences" } \\
\text { of the recommended flow regime. }\end{array}$ & Step E \\
\hline & & $\begin{array}{l}\text { 13. If "natural WQ impacts", use Q-C } \\
\text { modelling to motivate for Quantity Reserve. }\end{array}$ & $\begin{array}{l}\text { Recommended flow regime that } \\
\text { will attain RQOs for water quality. }\end{array}$ & Step E \\
\hline & & $\begin{array}{l}\text { 14.If required, use concentration exceedance } \\
\text { curves to assess recommended flow regime } \\
\text { compared to natural and present-day with } \\
\text { regard to WQ. }\end{array}$ & & \\
\hline \multirow{7}{*}{ 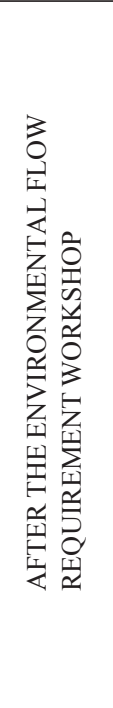 } & 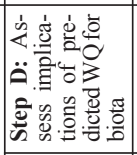 & $\begin{array}{l}\text { 15. Apply Biotic protocol to key IFR sites, } \\
\text { for recommended discharge regime. }\end{array}$ & $\begin{array}{l}\text { Predicted derived SASS scores, } \\
\text { ecological Reserve class, lists of } \\
\text { taxa. }\end{array}$ & Step E \\
\hline & \multirow{2}{*}{ 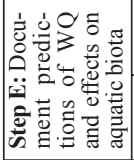 } & 16. Record results of WQ modelling. & Water quality modelling report. & Step F \\
\hline & & 17. Record results of Biotic protocol. & $\begin{array}{l}\text { Report on expected effects on the } \\
\text { aquatic biota. }\end{array}$ & \\
\hline & \multirow{3}{*}{ 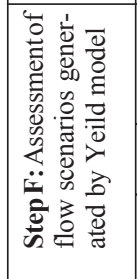 } & $\begin{array}{l}\text { 18. Use Q-C relationships to transform discharge } \\
\text { to concentration time-series for key sites. }\end{array}$ & & \\
\hline & & 19. Prepare concentration exceedance curves. & Concentration exceedance curves. & Step G \\
\hline & & 20. Rank flow scenarios with regard to WQ impact. & $\begin{array}{l}\text { Flow scenarios ranked w.r.t. water } \\
\text { quality implications. }\end{array}$ & Step G \\
\hline & 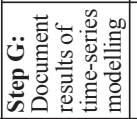 & 21. Record results of time-series modelling. & Report on flow scenario modelling. & \\
\hline
\end{tabular}




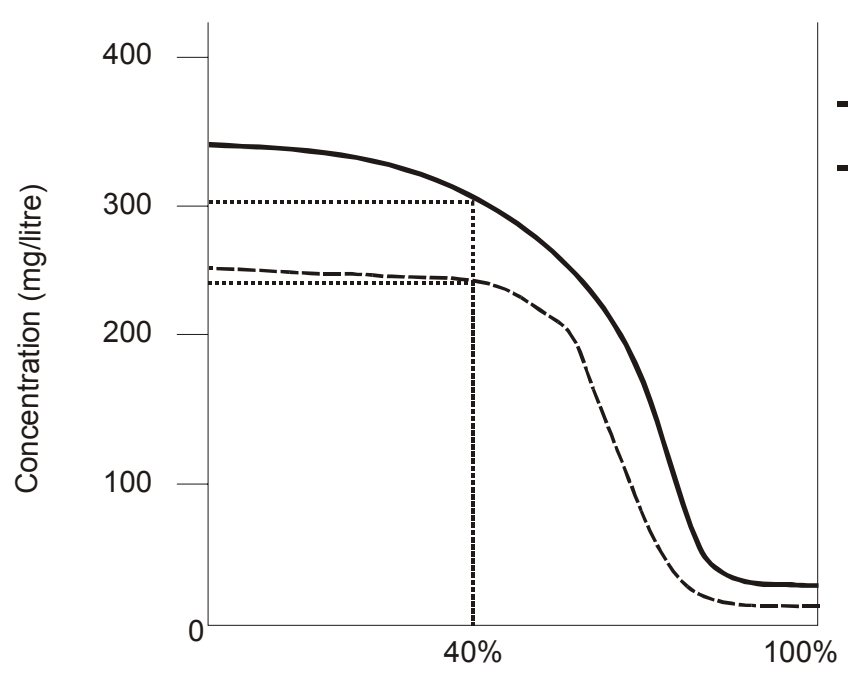

$\%$ Time equalled or exceeded

Figure 2

Concentration exceedance curves for two hypothetical flow scenarios (shown by solid and dashed lines respectively). The dotted line indicates that under Flow scenario 1, concentration will be equal to, or greater than $\approx 240 \mathrm{mg} / \mathrm{l}, 40 \%$ of the time. Under Flow scenario 2, concentration will be equal to, or greater than $\approx 310 \mathrm{mg} / \ell, 40 \%$ of the time.

pleteness. Water quality is defined for the reference condition and for the present ecological state and for individual river reaches and the appropriate level of protection is ascertained. For each water quality variable, the resource quality objectives, i.e. the concentration of chemical constituents or levels of physical variables that should not be exceeded, are assigned. Flow-concentration plots for each chemical constituent of concern (for which there are data) are drawn up for each site and the regression relationship determined.

- The second phase of the framework involves the tasks that arise during the EFR workshop. A workshop involving experts specialising in the various relevant disciplines (macroinvertebrates, riparian vegetation, fish, amongst others) is integral to the EFR process. Using expert opinion, as well as structured data analysis of various types, a flow regime is recommended by the specialists that can be expected to maintain the river ecosystem in a predetermined state, or class (King et al., 2000). The Q-C plots are employed to make predictions of water quality in response to the flow regime prescribed by the EFR practitioners and to assess whether under the recommended flow regimes the water quality Reserve will be met during all months of the year. Concentration exceedance curves can also be used at this stage to compare the water quality consequences arising from the natural, the present-day and the recommended flow regimes.

- The third phase of the process is carried out after the EFR workshop. The implications of the predicted water quality for the biota can be assessed. In other words, the likelihood of the resource quality objectives for aquatic macroinvertebrates being attained under the proposed flow regime, and current pollution loading, needs to be ascertained. Ideally, the results of this assessment should be fed back into the process, so that, if necessary the quantity component of the Reserve can be adjusted. Although, only in cases where high concentrations of a given chemical constituent occur due to natural causes, and
Flow scenario 1

Flow scenario 2

where the recommended flow regime would result in unnaturally elevated concentrations, should water quality be adjusted by means of dilution.

- Comparison of flow scenarios during a post-EFR workshop phase may, or may not, take place. Presently, such comparisons are made at a flow scenario workshop which is held if there are such heavy demands on the system in question that both the ecological Reserve and the demands of existing users in the catchment cannot be satisfied (Louw et al., 2000). Concentration exceedance curves can be used to compare and rank different flow scenarios with regard to the likely impact on water quality. In order to make realistic predictions of water quality it is necessary to take into account the various sources of water as well as the loads of pollutants that can contribute to the total flow at a particular site on a river. This is not currently part of the process. Although incorporation of such management scenarios might greatly increase the complexity of quantifying the Reserve, it is an essential step if a balance is to be maintained between the use of a water resource on the one hand and protection of the aquatic ecosystem on the other. The final step is to document the results of the scenario modelling phase.

\section{Conclusion}

There is a chain of cause and effect between altering the flow in a river, the resulting water quality and the implications of these changes for the aquatic biota. The development of the Q-C modelling method, the Biotic Protocol and the use of concentration timeseries to quantify such relationships have been brought about by participation in actual Reserve assessments. Further development of the methods is still needed and feedback is required from water resource managers in order to make the tools as useful and relevant as possible. This will be especially important as the ecological Reserve becomes implemented in South African rivers and resource quality objectives need to be met. Despite the approximations in and limitations of the methods, the use of the tools described in this paper will aid in the integration of water quality and quantity and should result in a more balanced approach to the use of water resources and enhanced protection of aquatic ecosystems.

\section{Acknowledgements}

Research into concentration exceedance curves has been carried out in collaboration with ProfC Palmer and ProfD Hughes of IWR, Rhodes University. The authors would also like to thank Dr A Bath (Water Corporation, Australia), Dr H Dallas (FRU, UCT) and Ms Rebecca Tharme for commenting on the manuscript. Finally the authors would like to express their appreciation to the Water Research Commission for funding this work (WRC Project Number $\mathrm{K} 5 / 956)$.

\section{References}

BROWN LC and BARNWELL TO (1987) The Enhanced Stream Water Quality Models QUAL2E and QUAL2E-UNCAS: Documentation and User Manual. US EPA/600/3-87/1007. 
CHUTTER FM (1998) Research on the Rapid Biological Assessment of Water Quality: Impacts in Streams and Rivers. WRC Report No. 422/ 1/98. Water Research Commission, Pretoria.

DALLAS HF and DAY JA (1993) The Effect of Water Quality Variables on Riverine Ecosystems: A Review. WRC Report No. TT 61/93. Water Research Commission, Pretoria, South Africa.

DALLAS HF and JANSSENS P (1998) The Biological and Chemical Database: User Manual. WRC Report No. TT 100/98. Water Research Commission, Pretoria.

DWAF (1996) South African Water Quality Guidelines. Vol 7: Aquatic Ecosystems. Department of Water Affairs and Forestry, Pretoria.

DWAF (1999) Resource Directed Measures for Protection of Water Resources. Institute for Water Quality studies, Department of Water Affairs and Forestry, Private Bag X313, Pretoria 0001.

FOWLER J, DALLAS H and JANSSENS P (2000) Rivers Database: A User Manual. NAEBP Report Series No 11. Institute for Water Quality Studies, Department of Water Affairs and Forestry, Pretoria,

GREGORY KJ and WALLING DE (1973) Drainage Basin Form and Process: A Geomorphological Approach. John Wiley and Sons, New York.

JENKINS A (1989) Storm period hydrochemical response in an unforested Scottish catchment. Hydrol. Sci. J. 34 393-404.

KING J and LOUW D (1998) Instream flow assessments for regulated rivers in South Africa using the Building Block Methodology. Aquat. Ecosyst. Health Manage. 1 109-124.

KING J, BROWN C and SABET H (in press ) A scenario-based holistic approach to environmental flow assessments for rivers. River Res. Appl.

KING JM, THARME RE and DE VILLIERS MS (2000) Environmental Flow Assessments for Rivers: Manual for the Building Block Methodology. WRC Report No: TT 131/00. Water Research Commission, Pretoria.

LOUW D, HUGHES D and BIRKHEAD A (2000) The IFR process: Beyond the specialist workshop. Afr. J. Aquat. Sci. 25 183-190.

MALAN HL and DAY JA (2002a) Linking Discharge, Water Quality and Biotic Response in Rivers: A Literature Review. WRC Report no. 956 2/02. Water Research Commission, Pretoria.

MALAN HL and DAY JA (2002b) Development of Numerical Methods for Predicting Relationships between Streamflow, Water Quality and Biotic Responses in Rivers. WRC Report No. 956/1/02. Water Research Commission, Pretoria.
MALAN H, BATH A, DAY J and JOUBERT A (2003) A simple flowconcentration modeling method for integrating water quality and water quantity in rivers. Water SA 29 (3) 305-312.

MILHOUS RT, UPDIKE MA and SCHNEIDER DM (1989) Physical Habitat Simulation System Reference Manual - Version II. Instream Flow Information. Paper No. 26, US Fish and Wildlife Service. Biol. Rep. 89 (16), Washington, D.C. 222 pp.

O'KEEFFE J (2000) Environmental flow assessments within the South African integrated planning process for water resources. In: King JM, De Villiers M, Tharme RE (eds.) Flow Assessments for Rivers: Manual for the Building Block Methodology. WRC Report No. TT 131/00, Water Research Commission, Pretoria.

PERRY J, VANDERKLEIN E and LEMONS J (1996) Water Quality: Management of a Natural Resource. Blackwell Science, Cambridge, USA.

PALMER C and ROSSOUW JN (2000) Water Quality: Olifants River Ecological Water Requirement Assessment. Dept. Water Affairs and Forestry, Report No. PB 000-00-5999. DWAF, Pretoria.

SCHERMAN P-A, PALMER CG and MULLER, WJ (2003) Use of Indigenous Riverine Invertebrates in Applied Toxicology and Water Resource-Quality Management. WRC Report No. 955/1/03. Water Research Commission, Pretoria.

SIDLE RC (1988) Bed load transport regime of a small forest stream. Water Resour. Res. 24 207-218.

SMITH MJ, KAY WR, EDWARD DHD, PAPAS PJ, RICHARDSON KJ, SIMPSON JC, PINDER AM, CALE DJ, HORWITZ PHJ, DAVIS JA, YUNG FH, NORRIS RH and HALSE SA (1999) AusRivAS: Using macroinvertebrates to assess ecological condition of rivers in Western Australia. Freshwater Biol. 41: 269-282.

THARME RE and KING JM (1998) Development of the Building Block Methodology for Instream Flow Assessments and Supporting Research on the Effects of Different Magnitude Flows on Riverine Ecosystems. WRC Report No. 576/1/98. Water Research Commission, Pretoria.

WADDLE T (1998) Integrating microhabitat and macrohabitat. In: Blazkova S, Stalnaker C and Novicky O (eds.) Hydroecological Modelling: Research, Practice, Legislation and Decision-Making. Report by U.S. Geological Survey Biological Research Division and Water Research Institute, Praha, Czech Republic. VUV, Praha. 12-14. 